\title{
Upregulation of glucose metabolism by NF- $\kappa$ B2/p52 mediates enzalutamide resistance in castration-resistant prostate cancer cells
}

\author{
Yuanyuan Cui ${ }^{1}$, Nagalakshmi Nadiminty ${ }^{1}$, Chengfei Liu', Wei Lou', Chad T Schwartz ${ }^{1}$ \\ and Allen C Gao ${ }^{1,2}$ \\ ${ }^{1}$ Department of Urology, University of California Davis Medical Center, 4645 2nd Avenue, Research, III, Suite 1300, \\ Sacramento, California 95817, USA \\ ${ }^{2}$ UC Davis Comprehensive Cancer Center, University of California Davis, California, USA
}

Correspondence should be addressed to A C Gao Email acgao@ucdavis.edu

\begin{abstract}
Cancer cells reprogram their metabolic pathways to facilitate fast proliferation. Previous studies have shown that overexpression of NF-kB2/p52 (p52) in prostate cancer cells promotes cell growth and leads to castration resistance through aberrant activation of androgen receptor (AR). In addition, these cells become resistant to enzalutamide. In this study, we investigated the effects of p52 activation on glucose metabolism and on response to enzalutamide therapy. Data analysis of gene expression arrays showed that genes including GLUT1 (SLC2A1), PKM2, G6PD, and ME1 involved in the regulation of glucose metabolism were altered in LNCaP cells overexpressing p52 compared with the parental LNCaP cells. We demonstrated an increased amount of glucose flux in the glycolysis pathway, as well as the pentose phosphate pathway (PPP) upon p52 activation. The p52-overexpressing cells increase glucose uptake and are capable of higher ATP and lactate production compared with the parental LNCaP cells. The growth of p52-overexpressing cells depends on glucose in the culture media and is sensitive to glucose deprivation compared with the parental LNCaP cells. Targeting glucose metabolism by the glucose analog 2-deoxy-D-glucose synergistically inhibits cell growth when combined with enzalutamide, and resensitizes p52-overexpressing cells to enzalutamide treatment. These results suggest that p52 modulates glucose metabolism, enhances glucose flux to glycolysis and PPPs, thus facilitating fast proliferation of the cells. Co-targeting glucose metabolism together with AR axis synergistically inhibits cell growth and restores enzalutamide-resistant cells to enzalutamide treatment.
\end{abstract}
Key Words
- prostate cancer
- glucose metabolism

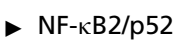
- enzalutamide

Endocrine-Related Cancer (2014) 21, 435-442

\section{Introduction}

As the second leading cause of cancer-related death among men in the United States, prostate tumors respond to androgen deprivation therapy initially; however, after time, relapse occurs and develops into a lethal form of disease, termed castration-resistance prostate cancer (CRPC; Chen et al. 2004, Harris et al. 2009). The NF-кB 
family has been identified as an important mediator in many cancer-causing processes. The family consists of five members: RelA/p65, NF-кB1/p50, c-Rel, RelB, and NF-kB2/p52, in which p65/p50 heterodimer and RelB/p52 heterodimer are involved in the canonical and non-canonical NF- $\kappa \mathrm{B}$ pathways respectively (Fan \& Maniatis 1991, Betts \& Nabel 1996, Lin et al. 1998, Karin \& Greten 2005). The non-canonical pathway that involves the processing of NF- $\mathrm{BB} 2$ p100 to p52 is inducible and tightly regulated (Xiao et al. 2001a,b, Xiao et al. 2004, Nadiminty et al. 2006). Overproduction of p52 from p100 causes hyperplastic growth in the liver, lymphocytes, and mammary glands of mice (Ishikawa et al. 1997, Connelly et al. 2007). In several solid tumors, including breast and prostate, overproduction of p52 has been observed (Cogswell et al. 2000, Lessard et al. 2006). In previous studies, we have shown that NF-кB2/p52 induces castration-resistant growth in prostate cancer cells through aberrant activation of androgen receptor (AR) (Nadiminty et al. 2008, 2010a). In addition, p52overexpressing cells are resistant to enzalutamide, a newly approved anti-androgen drug for CRPC patients (Tran et al. 2009, Nadiminty et al. 2013). Yet, the effect of p52 on cellular metabolism has not previously been studied.

Different from highly differentiated normal cells, cancer cells reprogram their metabolism to facilitate fast proliferation. One typical feature is known as the 'Warburg effect', also called aerobic glycolysis, where cancer cells mainly depend on glycolysis for their energy production in the presence of oxygen (Warburg 1956). This process produces far less energy than that oxidative phosphorylation exhibited in normal cells; however, it produces more intermediate products for anabolic building blocks and much less oxidative stress to keep the redox balance (Cairns et al. 2011, Vander Heiden 2011, DeBerardinis \& Thompson 2012, Teicher et al. 2012). It has been reported that metabolic enzymes such as pyruvate kinase can be alternatively spliced to isoform M2, which supports anabolic growth and promotes tumorigenesis (Christofk et al. 2008a, Sun et al. 2011). Activation of many oncogenes, such as PI3K (PIK3CA), AKT, mTORC1, and $M Y C$, can also impact metabolism of mitochondria (Berwick et al. 2002, Buzzai et al. 2005, Hatzivassiliou et al. 2005, Cunningham et al. 2007).

In this study, we demonstrated through gene expression array data analysis that genes involved in glucose metabolic pathways in p52-overexpressing LNCaP cells were upregulated. Further analysis on glucose metabolism revealed enhancements in both the glycolysis and pentose phosphate pathways (PPPs) accompanied by higher glucose consumption and lactate production. Moreover, targeting glucose metabolism by glucose analog 2-deoxy-D-glucose (2-DG) resensitized p52-overexpressing prostate cancer cells' response to enzalutamide.

\section{Materials and methods}

\section{Cell culture and reagents}

LNCaP and C4-2B cells were cultured in RPMI-1640 medium supplemented with $10 \%$ fetal bovine serum (FBS), 100 units $/ \mathrm{ml}$ penicillin, and $0.1 \mathrm{mg} / \mathrm{ml}$ streptomycin and maintained at $37^{\circ} \mathrm{C}$ in a humidified incubator with $5 \% \mathrm{CO}_{2}$. LNCaP-neo and LNCaP-p52 stable cells are generated as described previously (Nadiminty et al. 2010b). C4-2B MDVR cells were generated by culturing C4-2B cells in media containing $20 \mu \mathrm{M}$ enzalutamide until the cells became resistant to enzalutamide as described previously (Nadiminty et al. 2013). The cells were seeded in 24-well plates and treated with $20 \mu \mathrm{M}$ enzalutamide and/or $1 \mathrm{mM} / 2 \mathrm{mM}$ 2-DG after $24 \mathrm{~h}$. After $48-72 \mathrm{~h}$ of treatment, they were counted and harvested; medium was collected for glucose consumption, lactate production, and PSA concentration assays. 2-DG was purchased from Sigma-Aldrich. ATP assay kit was purchased from PerkinElmer (Santa Clara, CA, USA). Glucose consumption, lactate production, pyruvate kinase activity, and NADPH/NADP assay kits were all purchased from Biovision (Milpitas, CA, USA). PSA ELISA kit was purchased from Abnova (Walnut, CA, USA).

\section{Microarray pathway analysis}

Metabolic pathways of NF-кB2/p52 were analyzed using Ingenuity Pathway Analysis Software (Ingenuity). This method uses gene identities in conjunction with controlled, vocabulary-based data mining of literature associations, protein-protein interaction databases, and a metabolism pathway database.

\section{Preparation of whole-cell extracts}

Cells were washed twice with PBS and lysed for 20 min on ice with cell lysis buffer containing 10 mM HEPES, pH 7.9, $250 \mathrm{mM} \mathrm{NaCl}, 1 \mathrm{mM}$ EDTA, 1\% NP-40, supplemented with $1 \mathrm{mM}$ dithiothreitol, $1 \mathrm{mM}$ phenylmethylsulphonyl fluoride, $5 \mathrm{mM} \mathrm{NaF}, 1 \mathrm{mM} \mathrm{Na} \mathrm{NO}_{4}$, and protease inhibitors (Roche).

Published by Bioscientifica Ltd. 


\section{Western blot analysis}

The cell extracts were obtained and separated by SDSPAGE and the proteins transferred onto nitrocellulose membranes. The membranes were blocked by $5 \%$ non-fat milk in PBS/0.05\%Tween-20, followed by probing with appropriate primary and secondary antibodies.

\section{Cell transfection}

CWR22Rv1 cells were transiently transfected with HA tag-labeled p52 plasmid. The cells were plated at density of $1 \times 10^{5} / \mathrm{ml} 1$ day before transfection, which was done by Attractene (Qiagen) following the manufacturer's instruction.

\section{Measurement of ATP production, glucose consumption, and lactate production}

ATP levels in the cell lysate were determined by luminescence-based assay kit (ATPlite; PerkinElmer) according to the manufacturer's instruction. The cells were seeded in the culture dishes and the medium was changed after $12 \mathrm{~h}$. The culture medium was collected for the measurement of glucose and lactate concentration after 24-48 h. Glucose levels were determined by comparing difference in the collected medium and fresh medium using a glucose assay kit (Biovision). Lactate levels were measured by lactate assay kit (Biovision). ATP production, glucose consumption, and lactate production levels were normalized to cell number.

\section{NADPH/NADP assay}

The cells were harvested after $48 \mathrm{~h}$ of culture. NADP total (NADPH and NADP) levels and NADPH levels were determined by a commercially available assay kit (Biovision). NADP levels were determined by the difference between NADP total and NADPH levels. The ratio was calculated thereafter.

\section{Glucose deprivation assay}

The cells were seeded into 12-well plates 1 day before switching to an RPMI-1640 glucose-free medium containing $10 \%$ dialyzed FBS. The cells were counted 3 days after changing the medium.

\section{PSA ELISA assay}

Culture medium was collected 2 days after seeding cells or drug treatment. PSA levels in the medium were measured by a commercially available kit, following the manufacturer's instruction. Data are expressed as mean \pm s.D. from three independent experiments.

\section{Statistical analysis}

All data presented are shown as mean \pm s.D. Student's $t$-test was used to compare differences between two groups. $P<0.05$ was considered significant.

\section{Results}

\section{Alteration of glucose pathways by p52}

Our previous studies have demonstrated that p52overexpressing LNCaP prostate cancer cells are more aggressive in terms of tumour growth, resistance to androgen deprivation, and enzalutamide treatment (Nadiminty et al. 2006, 2008, 2010a,b, 2013). As it is well documented that cancer cells reprogram their metabolism to facilitate fast proliferation, we examined the metabolic pathways in p52-overexpressing LNCaP cells by analyzing the gene expression microarray data generated from p52 retrovirus-infected cells (Nadiminty et al. 2010b).

Of the top 30 altered pathways by overexpression of p52 in LNCaP cells compared with the parental LNCaP cells, the intermediate or final products of 11 pathways, including the top 2 pathways, are involved in sugar metabolism, fatty acid synthesis, and/or lipid biosynthesis and degradation. Five pathways are correlated to amines, polyamines, amino acids biosynthesis, and degradation. In addition, pathways involved in the biosynthesis and degradation of nucleoside and nucleotide as well as biosynthesis of vitamin, NAD, and polysaccharides are all significantly enhanced. The most altered metabolic pathways are listed in Fig. 1A. These findings suggest that in p52 cells, anabolic metabolism pathways are enhanced, providing additional byproducts necessary for cell division, thus facilitating quicker cell proliferation.

In correspondence with the enhanced macromolecular biosynthesis, glycolysis processes including fermentation of pyruvate to lactate are at top of the list. Many key enzymes within glycolysis, such as PFKP, GAPDHS, PGK1, ENO1, ENO3, PKM2, and LDHA, have elevated expression levels in LNCaP-p52 cells compared with the parental LNCaP cells (Fig. 1B). In addition to the upregulated genes in glycolysis, genes within the PPP, such as G6PD, PGD, TALDO1, and TKT, are also upregulated (Fig. 1B).

Published by Bioscientifica Ltd. 

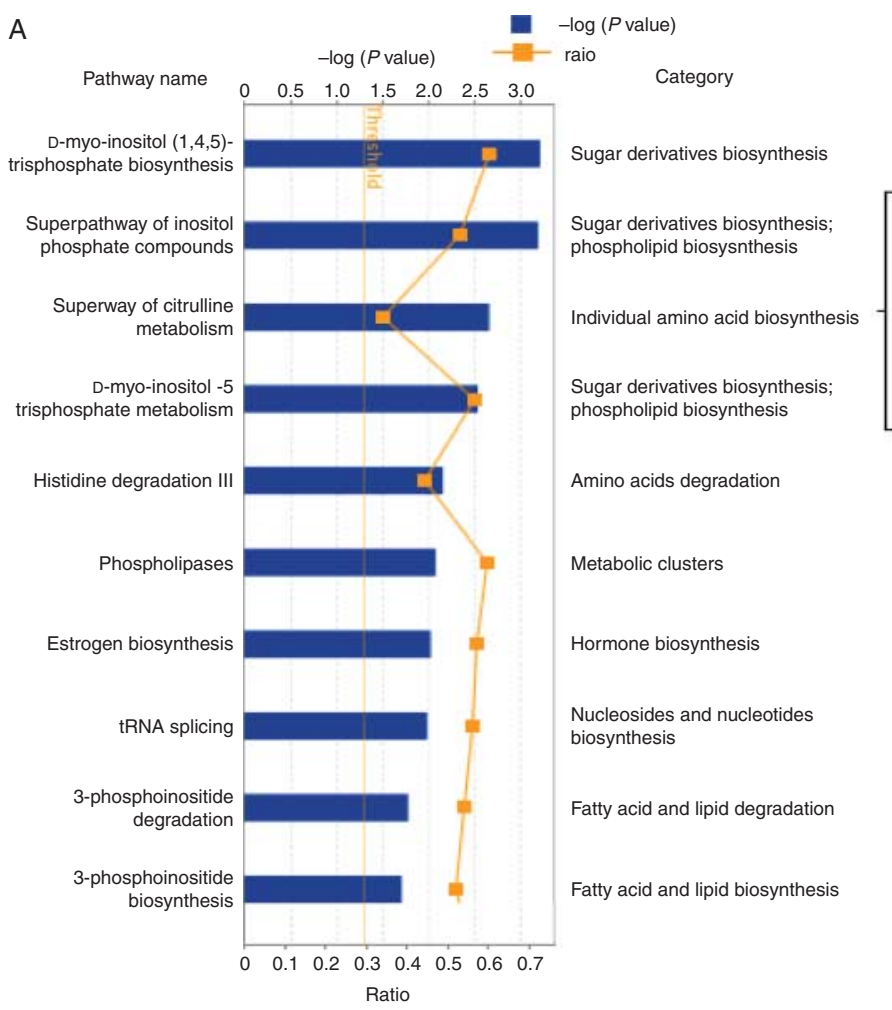

B

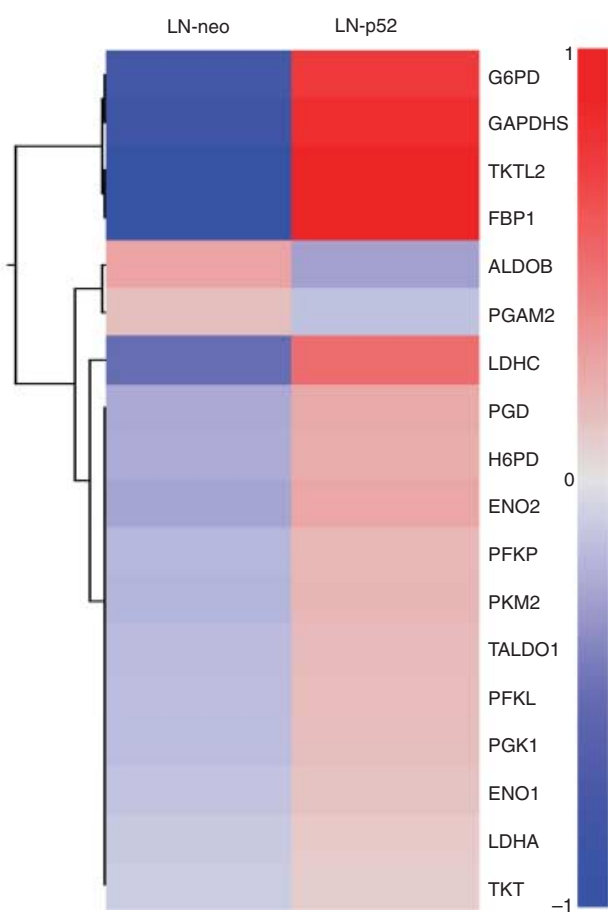

Figure 1

Metabolic pathways and genes altered in LNCaP-p52 cells. (A) Top 10 altered metabolic pathways are listed. Blue boxes show log ( $P$ value). Yellow dots show in $\log _{2}$ (fold change). Fold change threshold is set as 1.2. (B) Heat map of gene expression within glycolysis and pentose phosphate

\section{p52 enhances glucose metabolism}

Gene expression array data suggest the alteration of glucose metabolic pathway by p52 in LNCaP cells. To further understand reprogramed glucose metabolism by p52, we assayed several indicators within the glucose metabolic pathways. Glucose uptake is the first step in glucose metabolism, which can be measured by the expression levels of glucose transporter, GLUT1, and by glucose consumption assays. LNCaP-p52 cells expressed GLUT1 at higher levels compared with the control (Fig. 2A), consistent with higher glucose consumption in p52 overexpression cells compared with the control (Fig. 2B). These data suggest an increased glucose uptake and consumption by the cells overexpressing p52. As a rate-limiting final step of glycolysis, catalysis of PEP to pyruvate by PKM2, a splice isoform of pyruvate kinase, plays important roles in cancer metabolism. Expression of PKM2 has a growth advantage for tumor cells in vivo (Christofk et al. 2008a,b). Our gene expression array data indicated an increased expression of PKM2 mRNA by pathways. All genes of the glycolysis and pentose phosphate pathways with a $>1.2$-fold change are included in the heat map. Color scale shows the format of $\log _{2}$ (fold change).

overexpression of p52. To confirm whether p52 enhances PKM2 protein expression, we analyzed the expression of PKM2 and phosphorylated PKM2. As shown in Fig. 2A, the protein levels of both PKM2 and phosphorylated PKM2 were upregulated in LNCaP-p52 cells compared with the control. As cancer cells mainly generate energy from aerobic glycolysis of glucose, we measured ATP production as an indicator of aerobic glycolysis. The p52-overexpressing LNCaP cells are capable of generation of higher ATP production compared with the parental LNCaP cells (Fig. 2C). In addition to ATP production, lactate production was also increased in LNCaP-p52 cells compared with the parental LNCaP cells (Fig. 2D).

PPP is a branch shunt from glycolysis, which provides intermediate products for nucleoside synthesis, and more importantly provides reductants such as NADPH to maintain the redox balance of fast proliferating cells. The enzyme involved in the first step of PPP flux, G6PD, was upregulated in LNCaP-p52 cells (Fig. 3A). In addition, the NADPH:NADP ratio was also much higher in LNCaP-p52 cells than control cells (Fig. 3B), suggesting an overall

Published by Bioscientifica Ltd. 
A
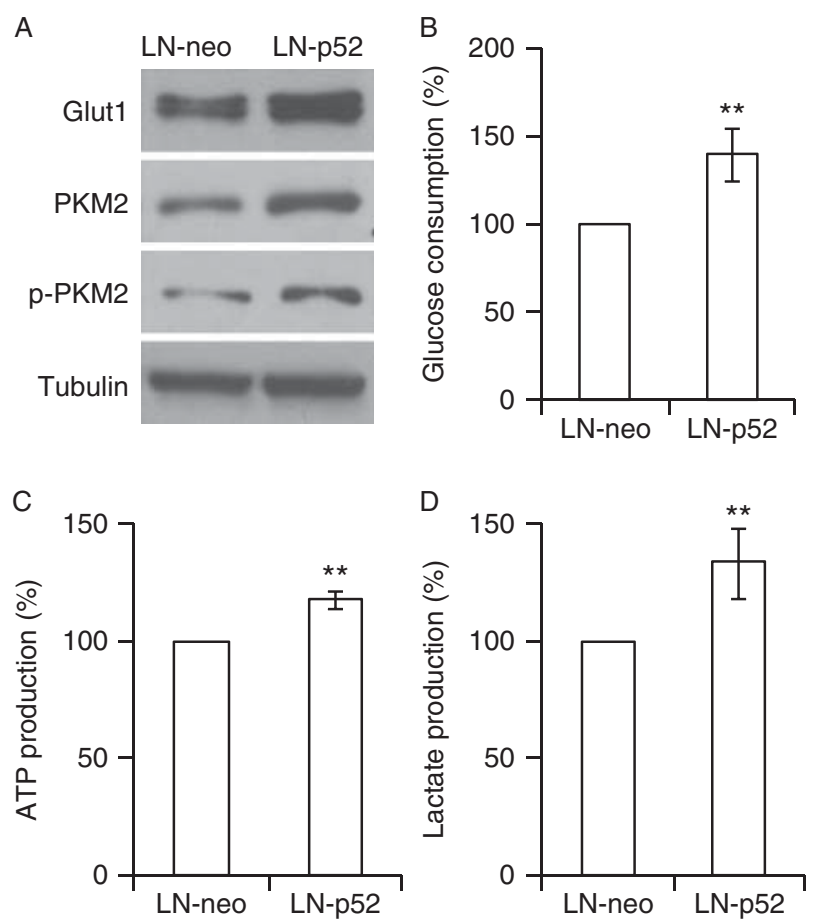

Figure 2

p52 increases LNCaP cells' glucose uptake and aerobic glycolysis. (A) Western blots for glucose transporter 1 (GLUT1), PKM2, phospho-PKM2. Tubulin was used as a loading control. Glucose consumption (B), ATP production (C), lactate production (D) of LNCaP-p52 cells compared with LNCaP-neo cells. Data are presented as mean \pm s.D. of at least three independent experiments. $* * P<0.01$.

enhanced PPP in LNCaP-p52 cells. To test whether p52-mediated glucose metabolism is not LNCaP cell specific, CWR22Rv1 cells were transiently transfected with p52. As shown in Fig. 3C, transient transfection of p52 increased PKM2 expression and glucose consumption in CWR22Rv1 cells (Fig. 3C). Collectively, these data suggest that overexpression of p52 enhances glucose metabolism in LNCaP cells.

\section{Overexpression of p52 increases cell sensitivity to glucose deprivation and 2-DG treatment}

As LNCaP-p52 cells have higher glucose uptake and rate of glucose metabolism, we hypothesized that p52-overexpressing LNCaP cells might be dependent on glucose for survival, and were more sensitive to glucose deprivation than parental LNCaP cells. To test that, we monitored cell growth in the absence of glucose. As shown in Fig. 4A, more cells were dead among p52-overexpressing LNCaP cells compared with the parental LNCaP cells when they grew in the media deprived of glucose. To further confirm this observation, we treated the cells with an analog of glucose, 2-DG, an inhibitor of glucose metabolism. As shown in Fig. 4B, p52-overexpressing LNCaP cells were more sensitive to 2-DG treatment than parental LNCaP cells. These results suggest that p52-overexpressing LNCaP cells are more sensitive to glucose deprivation than parental LNCaP cells.

\section{Targeting glucose metabolism by 2-DG resensitizes LNCaP-p52 cells to enzalutamide treatment}

Our previous studies have shown that LNCaP-p52 cells were resistant to enzalutamide treatment (Nadiminty et al. 2013). As LNCaP-p52 cells exhibit enhanced glucose consumption and are more sensitive to glucose deprivation and 2-DG treatment, we combined 2-DG with enzalutamide to examine whether the combination treatment could restore the cells' sensitivity to enzalutamide. As shown in Fig. 5A, a low dose of 2-DG (1 mM) combined with $20 \mu \mathrm{M}$ enzalutamide dramatically reduced LNCaP-p52 cell number.

We previously generated enzalutamide-resistant C4-2B MDVR cells (Nadiminty et al. 2013). Similar to
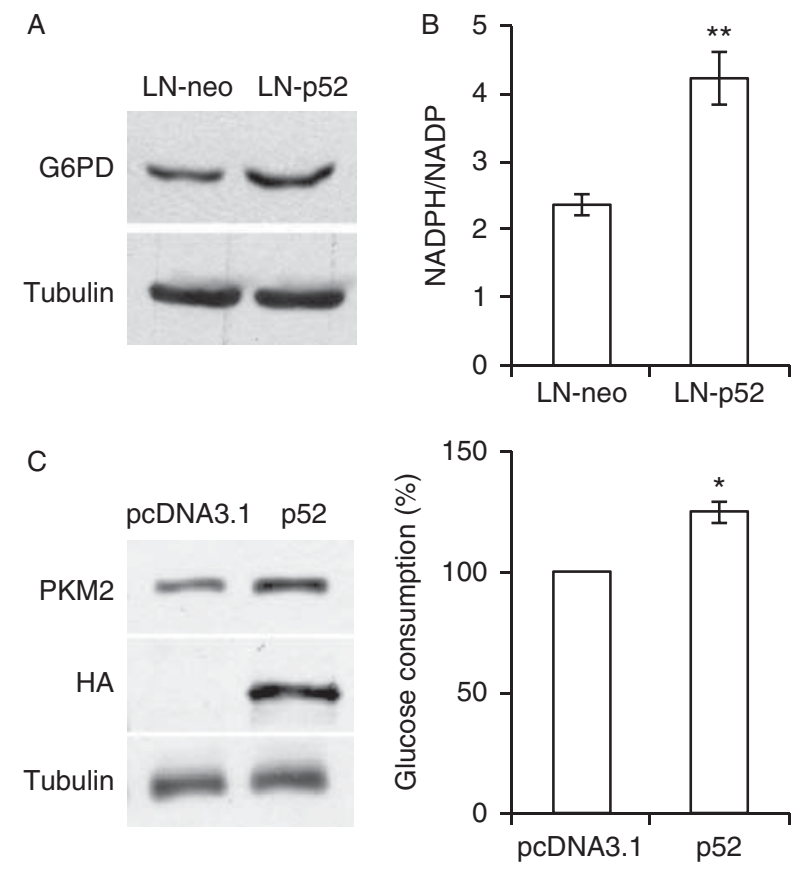

Figure 3

(A) Western blots for G6PD of LNCaP-neo and LNCaP-p52 cells. Tubulin was used as a loading control. (B) NADPH:NADP ratio of LNCaP-p52 cells compared with LNCaP-neo cells. (C) Transient transfection of p52 enhances glucose metabolism in CWR22Rv1 cells. Immunoblots of HA-tagged p52, PKM2, and tubulin in transiently transfected LNCaP cells (left). Glucose consumption assay in transient vehicle and p52 transfected CWR22Rv1 cells (right). Data was presented as mean \pm S.D. of three independent experiments. ${ }^{*} P<0.05,{ }^{*} P<0.01$. 

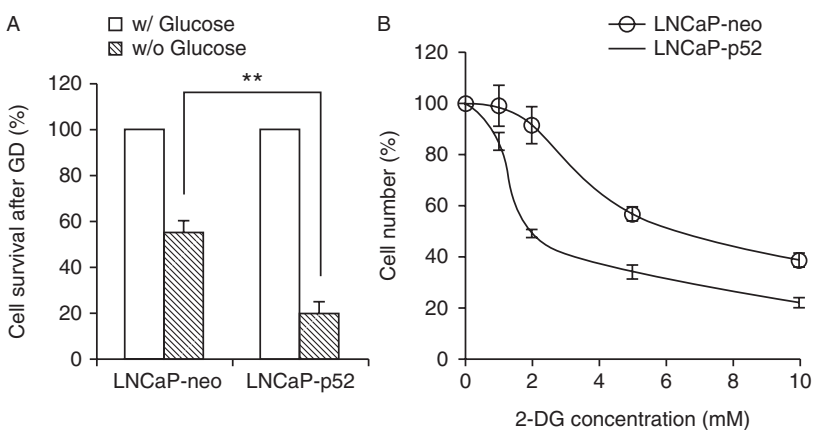

Figure 4

LNCaP-p52 cells are more sensitive to glucose deprivation and 2-DG treatment. (A) Cell growth comparison after 3 days of glucose deprivation. Cell numbers of LNCaP-neo and LNCaP-p52 cells in absence of glucose are normalized to the ones with glucose respectively. (B) Cell growth of LNCaP-p52 and LNCaP-neo at different concentrations of 2-DG. Data are presented as mean \pm s.D. in three independent experiments. ${ }^{* *} P<0.01$.

LNCaP-p52 cells, C4-2B MDVR cells have enhanced glucose consumption and ATP and lactate production (Fig. 5B). As 2-DG can greatly resensitize the response of LNCaPp52 cells to enzalutamide, we tested whether 2-DG would have a similar effect to MDV-resistant cells. Combination
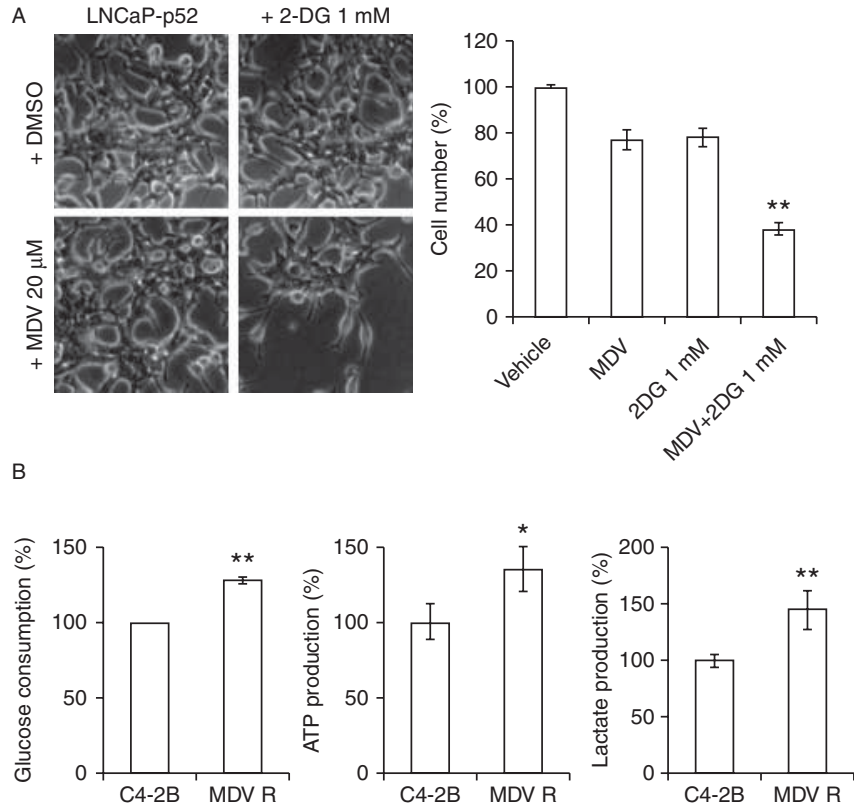

Figure 5

2-DG resensitizes cells to enzalutamide treatment. (A) Cell morphology of LNCaP-p52 cells was shown after 2 days treatment with 2-DG in combination with or without enzalutamide. Vehicle control and 2-DG treatment were shown in top panel. Enzalutamide and combination treatment with $1 \mathrm{mM}$ 2-DG were shown in bottom panel. (Right panel) Cell growth after 2 days of treatment. All numbers were normalized to vehicle group. Data were presented as mean \pm s.D. in at least three independent treatment with 2-DG and enzalutamide significantly decreased cell number in C4-2B MDVR cells (Fig. 5C and D). Collectively, these data suggest that targeting glucose metabolism can resensitize enzalutamide treatment in enzalutamide-resistant prostate cancer cells.

\section{Discussion}

Our previous studies have demonstrated that p52-overexpressing LNCaP cells grew significantly larger tumors in vivo, became castration-resistant through aberrant $\mathrm{AR}$ activation and resistant to enzalutamide treatment. Cancer cells have reprogramed metabolism to facilitate fast proliferation. In the present study, we analyzed glucose metabolism in $\mathrm{p} 52$-overexpressing prostate cancer cells, and found that glycolysis and PPP are both upregulated, indicating upregulation of glucose metabolism and ATP production by p52. Targeting glucose metabolism by 2-DG resensitizes the cell's response to enzalutamide of not only LNCaP-p52 cells, but also other enzalutamide-resistant cells, like C4-2B MDVR cells.
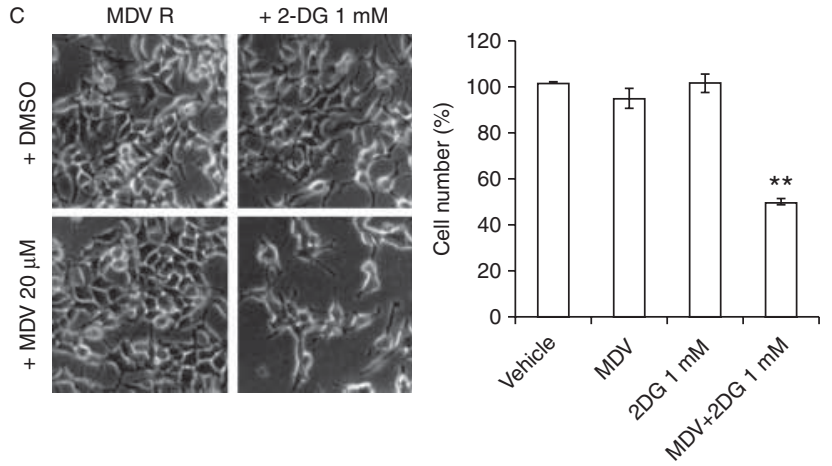

experiments. (B) Glucose consumption (left), ATP production (middle), and lactate production (right) in C4-2B MDVR enzalutamide-resistant cells compared with parental $C 4-2 B$ enzalutamide-sensitive cells. (C) 2-DG resensitizes C4-2B MDVR enzalutamide-resistant cells' response to enzalutamide treatment. Cell numbers were normalized to vehicle group. Data were presented as mean \pm s.D. in three independent experiments; $* P<0.05, * * P<0.01$

Published by Bioscientifica Ltd. 
The Warburg effect is a widely observed feature in tumors with elevated glucose uptake, glucose consumption, and lactate production. Several enzymes including GLUT1, PKM2, and LDHA are critically involved in glucose metabolism. We have shown that the levels of GLUT1 (SLC2A1), PKM2, and LDHA gene expression were upregulated in p52-overexpressing LNCaP cells, which correlated with higher glucose metabolism. The upregulation of these rate-limiting glucose metabolic enzymes may play a critical role in the p52-induced Warburg effect, featuring elevated glucose consumption and higher lactate production. One typical feature of cancer cells is switching energy production from oxidative phosphorylation to glycolysis to generate additional precursors for macromolecular biosynthesis. Gene expression microarray data analysis showed an enhanced macromolecular biosynthesis in p52-overexpressing LNCaP cells compared with the parental LNCaP cells, suggesting an enhanced production of building blocks for these macromolecules derived from glucose metabolites. This is in consistence with the upregulated glucose metabolism pathways observed in p52-overexpressing LNCaP cells.

Due to an altered glucose metabolism that cancer cells usually have, targeting glucose metabolism to inhibit cancer progression is an attractive approach for cancer therapy. 2-DG, a glucose analog, is the most widely investigated drug in experimental and clinical oncology (Dwarakanath \& Jain 2009). 2-DG is competitively taken up by cells through the same transporter as glucose and transformed by hexokinase to 2-DG-6-phosphate which cannot be metabolized further, therefore decreasing the glucose flux to glycolysis and PPPs. However, as a single therapeutic agent, the clinical trial of 2-DG has been discontinued due to persistent side effects such as diaphoresis and disturbance of the CNS (Dwarakanath et al. 2009, Gupta et al. 2009). A potential promising approach is to combine 2-DG therapy with radiation or chemotherapy drugs (Gupta et al. 2009). Enzalutamide, a newly approved anti-androgen drug, can effectively inhibit CRPC cell growth in vivo (Tran et al. 2009). Despite its successes and continuing widespread use, development of resistance is inevitable. Our previous studies have demonstrated that p52-overexpressing LNCaP cells were resistant to enzalutamide (Nadiminty et al. 2013). In the present study, we combined 2-DG and enzalutamide and found that a low dose of 2-DG resensitized the response of p52-overexpressing LNCaP cells to enzalutamide treatment. The combination of these two drugs has profound synergistic effects on the inhibition of cell growth. We further validated the synergistic effects of combination treatment of 2-DG with enzalutamide in another enzalutamide-resistant C4-2B-MDVR cells.

In summary, these results suggest that p52 modulates glucose metabolism and enhances glucose flux to glycolysis and PPPs, thus facilitating fast proliferation of the cells. Targeting glucose metabolism by deprivation of glucose or using glucose analog, such as 2-DG, inhibits cell growth. We found that combination treatment of 2-DG with enzalutamide could resensitize enzalutamideresistant prostate cancer cells to enzalutamide treatment, suggesting a potential therapeutic approach for CRPC patients, by co-targeting glucose metabolism and AR pathways.

\section{Declaration of interest}

The authors declare that there is no conflict of interest that could be perceived as prejudicing the impartiality of the research reported.

\section{Funding}

This work is supported in part by grants NIH/NCI CA140468, CA168601, CA179970, and US Department of Veterans Affairs, Office of Research and Development VA Merits 101 BX000526 (A C Gao), and by resources from the VA Northern California Health Care System, Sacramento, California.

\section{References}

Berwick DC, Hers I, Heesom KJ, Moule SK \& Tavare JM 2002 The identification of ATP-citrate lyase as a protein kinase B (Akt) substrate in primary adipocytes. Journal of Biological Chemistry 277 33895-33900. (doi:10.1074/jbc.M204681200)

Betts JC \& Nabel GJ 1996 Differential regulation of NF-кB2(p100) processing and control by amino-terminal sequences. Molecular and Cellular Biology 16 6363-6371.

Buzzai M, Bauer DE, Jones RG, Deberardinis RJ, Hatzivassiliou G, Elstrom RL $\&$ Thompson CB 2005 The glucose dependence of Akt-transformed cells can be reversed by pharmacologic activation of fatty acid $\beta$-oxidation. Oncogene 24 4165-4173. (doi:10.1038/sj.onc.1208622)

Cairns RA, Harris IS \& Mak TW 2011 Regulation of cancer cell metabolism. Nature Reviews. Cancer 11 85-95. (doi:10.1038/nrc2981)

Chen CD, Welsbie DS, Tran C, Baek SH, Chen R, Vessella R, Rosenfeld MG \& Sawyers CL 2004 Molecular determinants of resistance to antiandrogen therapy. Nature Medicine 10 33-39. (doi:10.1038/nm972)

Christofk HR, Vander Heiden MG, Harris MH, Ramanathan A, Gerszten RE, Wei R, Fleming MD, Schreiber SL \& Cantley LC 2008a The M2 splice isoform of pyruvate kinase is important for cancer metabolism and tumour growth. Nature 452 230-233. (doi:10.1038/nature06734)

Christofk HR, Vander Heiden MG, Wu N, Asara JM \& Cantley LC $2008 b$ Pyruvate kinase M2 is a phosphotyrosine-binding protein. Nature $\mathbf{4 5 2}$ 181-186. (doi:10.1038/nature06667)

Cogswell PC, Guttridge DC, Funkhouser WK \& Baldwin AS Jr 2000 Selective activation of NF- $\mathrm{B}$ subunits in human breast cancer: potential roles for NF-кB2/p52 and for Bcl-3. Oncogene 19 1123-1131. (doi:10.1038/ sj.onc.1203412)

Connelly L, Robinson-Benion C, Chont M, Saint-Jean L, Li H, Polosukhin VV, Blackwell TS \& Yull FE 2007 A transgenic model reveals 
important roles for the NF- $\mathrm{B}$ alternative pathway (p100/p52) in mammary development and links to tumorigenesis. Journal of Biological Chemistry 282 10028-10035. (doi:10.1074/jbc.M611300200)

Cunningham JT, Rodgers JT, Arlow DH, Vazquez F, Mootha VK \& Puigserver P 2007 mTOR controls mitochondrial oxidative function through a YY1-PGC-1 $\alpha$ transcriptional complex. Nature 450 736-740. (doi:10.1038/nature06322)

DeBerardinis RJ \& Thompson CB 2012 Cellular metabolism and disease: what do metabolic outliers teach us? Cell 148 1132-1144. (doi:10.1016/ j.cell.2012.02.032)

Dwarakanath B \& Jain V 2009 Targeting glucose metabolism with 2-deoxy-D-glucose for improving cancer therapy. Future Oncology $\mathbf{5}$ 581-585. (doi:10.2217/fon.09.44)

Dwarakanath BS, Singh D, Banerji AK, Sarin R, Venkataramana NK, Jalali R, Vishwanath PN, Mohanti BK, Tripathi RP, Kalia VK et al. 2009 Clinical studies for improving radiotherapy with 2-deoxy-D-glucose: present status and future prospects. Journal of Cancer Research and Therapeutics 5 (Suppl 1) S21-S26. (doi:10.4103/0973-1482.55136)

Fan CM \& Maniatis T 1991 Generation of p50 subunit of NF- - B by processing of p105 through an ATP-dependent pathway. Nature $\mathbf{3 5 4}$ 395-398. (doi:10.1038/354395a0)

Gupta S, Farooque A, Adhikari JS, Singh S \& Dwarakanath BS 2009 Enhancement of radiation and chemotherapeutic drug responses by 2-deoxy-D-glucose in animal tumors. Journal of Cancer Research and Therapeutics 5 (Suppl 1) S16-S20. (doi:10.4103/0973-1482.55135)

Harris WP, Mostaghel EA, Nelson PS \& Montgomery B 2009 Androgen deprivation therapy: progress in understanding mechanisms of resistance and optimizing androgen depletion. Nature Clinical Practice Urology 6 76-85. (doi:10.1038/ncpuro1296)

Hatzivassiliou G, Zhao F, Bauer DE, Andreadis C, Shaw AN, Dhanak D, Hingorani SR, Tuveson DA \& Thompson CB 2005 ATP citrate lyase inhibition can suppress tumor cell growth. Cancer Cell 8 311-321. (doi:10.1016/j.ccr.2005.09.008)

Ishikawa H, Carrasco D, Claudio E, Ryseck RP \& Bravo R 1997 Gastric hyperplasia and increased proliferative responses of lymphocytes in mice lacking the $\mathrm{COOH}$-terminal ankyrin domain of NF-кB2. Journal of Experimental Medicine 186 999-1014. (doi:10.1084/jem.186.7.999)

Karin M \& Greten FR 2005 NF-кB: linking inflammation and immunity to cancer development and progression. Nature Reviews. Immunology $\mathbf{5}$ 749-759. (doi:10.1038/nri1703)

Lessard L, Karakiewicz PI, Bellon-Gagnon P, Alam-Fahmy M, Ismail HA, Mes-Masson AM \& Saad F 2006 Nuclear localization of nuclear factor- $\kappa B$ p65 in primary prostate tumors is highly predictive of pelvic lymph node metastases. Clinical Cancer Research 12 5741-5745. (doi:10.1158/ 1078-0432.CCR-06-0330)

Lin X, Mu Y, Cunningham ET Jr, Marcu KB, Geleziunas R \& Greene WC 1998 Molecular determinants of NF-kB-inducing kinase action. Molecular and Cellular Biology 18 5899-5907.
Nadiminty N, Lou W, Lee SO, Lin X, Trump DL \& Gao AC 2006 Stat3 activation of NF- $\mathrm{KB}$ p100 processing involves $\mathrm{CBP} / \mathrm{p} 300$-mediated acetylation. PNAS 103 7264-7269. (doi:10.1073/pnas.0509808103)

Nadiminty N, Chun JY, Lou W, Lin X \& Gao AC 2008 NF-kB2/p52 enhances androgen-independent growth of human LNCaP cells via protection from apoptotic cell death and cell cycle arrest induced by androgen-deprivation. Prostate 68 1725-1733. (doi:10.1002/pros. 20839)

Nadiminty N, Lou W, Sun M, Chen J, Yue J, Kung HJ, Evans CP, Zhou Q \& Gao AC $2010 a$ Aberrant activation of the androgen receptor by NF-kB2/p52 in prostate cancer cells. Cancer Research 70 3309-3319. (doi:10.1158/0008-5472.CAN-09-3703)

Nadiminty N, Dutt S, Tepper C \& Gao AC $2010 b$ Microarray analysis reveals potential target genes of NF-кB2/p52 in LNCaP prostate cancer cells. Prostate 70 276-287. (doi:10.1002/pros.21062)

Nadiminty N, Tummala R, Liu C, Yang J, Lou W, Evans CP \& Gao AC 2013 $\mathrm{NF}-\kappa \mathrm{B} 2 / \mathrm{p} 52$ induces resistance to enzalutamide in prostate cancer: role of androgen receptor and its variants. Molecular Cancer Therapeutics 12 1629-1637. (doi:10.1158/1535-7163.MCT-13-0027)

Sun Q, Chen X, Ma J, Peng H, Wang F, Zha X, Wang Y, Jing Y, Yang H, Chen $\mathrm{R}$ et al. 2011 Mammalian target of rapamycin up-regulation of pyruvate kinase isoenzyme type M2 is critical for aerobic glycolysis and tumor growth. PNAS 108 4129-4134. (doi:10.1073/pnas. 1014769108)

Teicher BA, Linehan WM \& Helman LJ 2012 Targeting cancer metabolism. Clinical Cancer Research 18 5537-5545. (doi:10.1158/1078-0432.CCR12-2587)

Tran C, Ouk S, Clegg NJ, Chen Y, Watson PA, Arora V, Wongvipat J, Smith-Jones PM, Yoo D, Kwon A et al. 2009 Development of a second-generation antiandrogen for treatment of advanced prostate cancer. Science 324 787-790. (doi:10.1126/science.1168175)

Vander Heiden MG 2011 Targeting cancer metabolism: a therapeutic window opens. Nature Reviews. Drug Discovery 10 671-684. (doi:10.1038/nrd3504)

Warburg O 1956 On the origin of cancer cells. Science 123 309-314. (doi:10.1126/science.123.3191.309)

Xiao G, Cvijic ME, Fong A, Harhaj EW, Uhlik MT, Waterfield M \& Sun SC 2001a Retroviral oncoprotein Tax induces processing of NF-кB2/p100 in T cells: evidence for the involvement of IKK $\alpha$. EMBO Journal $\mathbf{2 0}$ 6805-6815. (doi:10.1093/emboj/20.23.6805)

Xiao G, Harhaj EW \& Sun SC $2001 b$ NF- $\mathrm{kB}$-inducing kinase regulates the processing of NF-кB2 p100. Molecular Cell 7 401-409. (doi:10.1016/ S1097-2765(01)00187-3)

Xiao G, Fong A \& Sun SC 2004 Induction of p100 processing by

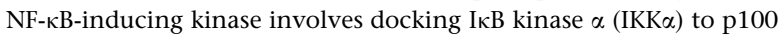
and IKKa-mediated phosphorylation. Journal of Biological Chemistry 279 30099-30105. (doi:10.1074/jbc.M401428200)

Received in final form 19 March 2014

Accepted 21 March 2014

Made available online as an Accepted Preprint

21 March 2014 http://erc.endocrinology-journals.org DOI: 10.1530/ERC-14-0107
(C) 2014 Society for Endocrinology Printed in Great Britain
Published by Bioscientifica Ltd. 